\title{
Erratum to: The distribution mechanism of noise fluxes between three oscillating modes of a free-running class-A laser
}

\author{
E. Khalilzadeh ${ }^{1} \cdot$ J. Jahanpanah $^{1}$
}

Published online: 30 April 2016

(C) Springer-Verlag Berlin Heidelberg 2016

Erratum to: Appl. Phys. B (2016) 122:67

DOI 10.1007/s00340-016-6324-0

In the original publication, the first and last name of the second author in reference [5] is incorrect. The correct reference [5] is given below.

\section{Reference}

5. A. Fiasconaro, B. Spagnolo, Phys. Rev. E 80, 041110 (2009)

\section{The online version of the original article can be found under} doi:10.1007/s00340-016-6324-0.

J. Jahanpanah

jahanpanah@khu.ac.ir

1 Physics Faculty, Kharazmi University, 49 Mofateh Ave, Tehran 15614, Iran 